\title{
Fluorodeoxygalactose F-18
}

National Cancer Institute

\section{Source}

National Cancer Institute. Fluorodeoxygalactose F-18. NCI Thesaurus. Code C94212.

A radioconjug ate containing the D-galactose analogue 2-deoxy-2-fluoro-D-galactose

(FDGal) labeled with the positron-emitting radioactive isotope fluorine F18, used for imaging upon positron emitting tomography (PET). With cell uptake much higher in tumor cells compared to normal cells, the F18 moiety of fluorodeoxyg alactose F-18 can be visualized upon PET imaging and this agent can be used as a tracer for the evaluation of galactose tumor uptake and metabolism. 